\title{
Editorial: Risk Management Models and Theories
}

\author{
Simon Grima ${ }^{1 *}$, Jonathan V. Spiteri ${ }^{1}$ and Eleftherios Thalassinos ${ }^{2}$ \\ ${ }^{1}$ Department of Insurance, Faculty of Economics, Management and Accountancy, University of Malta, Msida, Malta, \\ ${ }^{2}$ Department of Maritime Studies, University of Piraeus, Piraeus, Greece
}

Keywords: risk models, risk management, risk measurement, risk forecasting, risk theories

\section{Editorial on the Research Topic}

\section{Risk Management Models and Theories}

The aim of this Research Topic_- "Risk Management Models and Theories" is to create a platform for authors to explore, analyze and discuss current and innovative financial models and theories that firms use/prescribe to determine, measure, monitor, forecast, and manage risk in the face of disruptors, such as the increased use of artificial intelligence and technology, change in regulations, climate change, etc.

Since the topic of Risk Management is quite vast, contributions in this first issue are related to various areas. One of these areas explored financial risks and derivative use by non-financial companies in Turkey, wherein the author studied the financial risks arising from the activities of non-financial companies in BIST 100 index operating in Turkey, and the derivatives used in the management of these risks. He found that the risks that the companies were exposed to included credit risk, liquidity risk, interest risk, currency risk, and other risks and only half of the companies, on average, used derivatives in the management of these risks. In addition, he observed that they hedged themselves against currency risks through futures contracts and used more derivatives in the transportation and energy sectors. Besides, it was noted that the companies using derivative products are big and low liquid companies.

One author's contribution related to the evaluation of credit counterparty risk of American options via the Monte Carlo methods. He established a comparison between the Tilley Bundling and Longstaff-Schwartz LSM. Here, the author explained the steps involved in evaluating the value of an American option and how these can be extended to evaluate risk metrics.

Another contribution was provided on risk measures and inequality, wherein the authors' objective was to present the inequality evolution through the evolution of the top 1\%'s income share, while simultaneously attempting to connect and compare the performance of alternative ARCH/GARCH univariate models for the estimation of 95\% Value-at-Risk (VaR) and 95\% Expected Shortfall (ES) measures for three equity indices. They noticed that business cycles are present in risk measures as in the inequality measures and highlighted that at the beginning of 2014 there are low values of $\mathrm{VaR}$, and at the same time, the top $1 \%$ share increases in 3 out of the 4 countries studied. However, the opposite held for the period just before 2014. They note that this could be an indication that risk measures are not closely related to income inequality.

We also had a contribution on the exchange rate pass-through investigation for the Turkish economy, wherein the author investigated the effect of exchange rate changes on the producer and consumer prices in Turkey by using the VAR model. He found that the degree of transition with effect-response does function and that the prices were affected by variance decomposition by using the 2005-2019 monthly data. He found that the CPI's response to the change in nominal exchange rate was found to be greater than the PPI, and that the end of the impact is shorter than CPI's impact. 
Another author contributed to the volatility spillover between stock prices and trading volume during the pre-, in- and post global financial crisis periods. Herein, she found the existence of bidirectional volatility spillovers between stock price and trading volume in the pre- and post-crisis periods, and noted that in the crisis period, there is a unidirectional volatility spillover from stock prices to trading volume. This indicated that while the volatility of stock price affects the trading volume with lags in the crisis period, the volatility of stock price and that of trading volume in the non-crisis periods affect each other.

We also have a contribution on the volatility and shock transmission patterns between the BIST sustainability and BIST 100 indices. The aim of the authors in this case was to empirically investigate the volatility and shock transmission patterns between the BIST 100 index and the relatively new BIST sustainability index, which is a platform for companies with high performance on the international sustainability criteria. They utilized 678 daily data from $05 / 11 / 2014$, the day the XSURD Index was launched, to $31 / 08 / 2017$. The analysis employed a bivariate BEKK-GARCH $(1,1)$ model and findings indicate the existence of bidirectional volatility spillovers between the two indices. Additionally, they show that current volatility is affected by its past volatility for each index. As for the shock transmission, they show that the BIST Sustainability Index is responsive to both its shocks and shocks arriving from the BIST 100 Index, notwithstanding that the BIST 100 Index responds only to its shocks without any significant shock transmission from the BIST Sustainability Index.
Moreover, we find a contribution relating to the ways in which developed and developing stock markets reacted to the Dow Jones during the 2008 crisis. Here, the authors find that the developed and emerging stock markets react differently to the DJIA.

As can be noted from the above paragraphs, the contributions and findings of the first issue of this topic are quite focused around the area of finance and related to studies of current and during-crisis practices, tools, techniques and financial instruments used by the Risk Manager to manage identified exposures to risks. Therefore, the issue is aimed at the interest of academics and practitioners in this field.

\section{AUTHOR CONTRIBUTIONS}

All authors listed have made a substantial, direct and intellectual contribution to the work, and approved it for publication.

Conflict of Interest: The authors declare that the research was conducted in the absence of any commercial or financial relationships that could be construed as a potential conflict of interest.

Copyright $\odot 2020$ Grima, Spiteri and Thalassinos. This is an open-access article distributed under the terms of the Creative Commons Attribution License (CC BY). The use, distribution or reproduction in other forums is permitted, provided the original author(s) and the copyright owner(s) are credited and that the original publication in this journal is cited, in accordance with accepted academic practice. No use, distribution or reproduction is permitted which does not comply with these terms. 